\title{
Quality of Diet, Body Position, and Time after Feeding Influence Behavioral States in Low Birth Weight Infants
}

\author{
RAKESH SAHNI, DEEPAK SALUJA, KARL F. SCHULZE, SUDHA KASHYAP, \\ KIYOKO OHIRA-KIST, WILLIAM P. FIFER, AND MICHAEL M. MYERS \\ Departments of Pediatrics [R.S., D.S., K.F.S., S.K., K.O.-K.] and Psychiatry [W.P.F., M.M.M.], College of \\ Physicians and Surgeons, Columbia University, New York, New York 10032, U.S.A., and Division of \\ Developmental Psychobiology, New York State Psychiatry Institute, New York, New York 10032, U.S.A.
}

[W.P.F., M.M.M.]

\begin{abstract}
The effects of variations in carbohydrate and fat intake and body position on behavioral activity states were evaluated in 64 healthy, growing low birth weight infants (birth weight, 750$1600 \mathrm{~g}$ ). The infants, enrolled in a prospective, randomized, double-blind, controlled study of effects of quality of dietary energy, were fed one of the five formulas. These formulas contained fixed intakes of protein $(4 \mathrm{~g} / \mathrm{kg}$ per day) but different intakes of carbohydrate ( 9.1 to $20.4 \mathrm{~g} / \mathrm{kg}$ per day) and fat (4.3 to $9.5 \mathrm{~g} / \mathrm{kg}$ per day). Six-hour daytime sleep studies were performed at 2-wk intervals from time of full enteral intake until discharge (mean postconceptional age at first study, 33.2 $\pm 1.8 \mathrm{wk}$ ). Infants were randomly assigned to the prone or supine position for the first 3-h postprandial period; the position was reversed during the second $3 \mathrm{~h}$. Behavioral activity state, i.e. quiet sleep (QS), active sleep, indeterminate sleep, awake, or crying was coded each minute throughout the postprandial period. The overall incidence of QS was almost double in the prone position versus the supine $(p<0.0001)$. In contrast, the probability of being in either of the two wakeful states (awake and crying) was increased when infants were placed in supine position $(p<0.0001)$. Increased likelihood of being in QS while prone was found only during the $30 \mathrm{~min}$ after and before feeding in a 150-min prandial cycle. In contrast, increased amounts of awake and crying in supine position were observed throughout the feeding interval. As car-
\end{abstract}

\section{ABSTRACT}

bohydrate intake increased, time spent in QS in supine position increased (from $8.6 \%$ to $12.5 \%, p<0.02$ ), and a trend in the same direction was noted for the prone position $(p=0.06)$. However, during postprandial minutes $10-100$, when QS is likely to be entrained by the nutrient intake, enhancement of QS was found in the prone position only $(p<0.02)$. Carbohydrate intake influences the total time spent and the distribution of behavioral activity states within the postprandial period in low birth weight infants. The effect of nutrient intake on sleep profile is dependent on body position and time after feed. Mechanistic hypotheses relating sudden infant death syndrome to sleeping position may need to take these observations into account.

(Pediatr Res 52: 399-404, 2002)

LBW, low birth weight
BW, birth weight
CHO, carbohydrate
QS, quiet sleep
AS, active sleep
IND, indeterminate sleep
AW, awake
SIDS, sudden infant death syndrome

SIDS is the major cause of death in infants 1 to 12 mo of age, and accounts for nearly $30 \%$ of deaths during the postneonatal period (1). However, physiologic mechanisms that underlie this syndrome remain unknown. Nearly all clinical

Received October 9, 2001; accepted January 15, 2002.

Correspondence and reprint requests: Rakesh Sahni, M.D., Department of Pediatrics, College of Physicians and Surgeons, Columbia University, 630 W. 168th Street, New York, NY 10032, U.S.A.; e-mail: rs62@columbia.edu

Supported by U.S. Public Health Service Grants HD13063, HD27564, and HD32774, and a Clinical Research Center grant RR00645.

DOI: 10.1203/01.PDR.0000025343.22080.71 information regarding SIDS is based on retrospective data derived from the general population. Although accurate, prospective identification of individual infants who are likely to succumb is not yet possible, several risk factors associated with this syndrome have been identified. Among these factors, LBW associated with premature delivery stands out as one of the important factors (2-4). This finding suggests that systematic studies in LBW infants might provide key information concerning the physiologic disturbance that underlies SIDS.

During the last several years there is growing evidence that body position during sleep is related to the incidence of SIDS 
(5-9). In 1992, after review by the National Institute of Child Health and Human Development of the international evidence, the American Academy of Pediatrics Task Force on Infant Positioning and SIDS recommended that healthy term infants be positioned on their side or back when put down to sleep (10). After publication of these guidelines, the prevalence of infants placed in the prone position declined by $66 \%$ between 1992 and 1996 in the United States, and although causality cannot be proved, SIDS rates also declined approximately $38 \%$ during this period (11). This convincing association between sleeping position and susceptibility to SIDS and the known benefits of improved ventilation and lung mechanics in prone positioning in LBW infants (12-16) have led to renewed interest in the physiologic effects of body positioning. In previous studies of preterm $(17,18)$, term $(19-21)$, and older infants (22), it was observed that in the prone position infants spent more time in QS and less time AW. However, sleep states can be affected by many other factors such as time after feeding and the quality of the diet. In normal term infants studied repeatedly from 1 wk to 6 mo of age, Harper and colleagues (23) noted that the sequence and cyclicity of AS followed by QS was more predictable after feeding than after nonfeeding periods of wakefulness. From these findings, it was suggested that feeding serves to reset mechanisms that regulate the timing of sleep-state cycles. This observation was supported by reports that the prone sleeping position is associated with a 79\% increase in QS and a 71\% decrease in time AW, and the decreases in time AW are found throughout the interfeed interval, whereas increases in QS are found only within the first hour and again near the end of the interfeed interval (18). Also, data from our laboratory indicate that LBW infants receiving high protein intakes and gaining weight rapidly spent significantly more time in AS (24). Taken together, these observations suggest that both the amount and quality of the diet and the time after feeding interact with body position during sleep to alter behavior and physiology during the postprandial period. This investigation was designed to test the hypotheses that the effect of body position on the behavioral activity states is dependent on the quantity of nonprotein energy intake and that the effects of energy intake vary with the time after feeding.

\section{METHODS}

Study population. The study population consisted of 64 healthy, growing LBW infants (BW, 750-1600 g), ranging from 26 to $37 \mathrm{wk}$ in gestational age, all of whom were enrolled in a prospective, double-blind, controlled study of effects of quality of dietary energy on rate and composition of weight gain. The studies were approved by the Institutional Review Board, and written consent was obtained from the parents of all infants. All infants were nursed in room air, were free of apnea of prematurity, and were receiving no cardiac or respiratory medications. None had sonographic evidence of CNS pathologic disease at the time of the studies. The characteristics of the infants are shown in Table 1.

Dietary intake. Infants were prospectively fed one of five specially made experimental formulas. All formulas were designed to provide protein intakes of $4 \mathrm{~g} / \mathrm{kg}$ per day when fed at $180 \mathrm{~mL} / \mathrm{kg}$ per day. Formulas 1,3 , and 4 were designed to provide $130 \mathrm{kcal} / \mathrm{kg}$ per day when fed at the same volume. The $\mathrm{CHO}$ and fat contents of the formulas were varied to provide $35 \%$ of the nonprotein energy as $\mathrm{CHO}$ in formula $1,50 \%$ of the nonprotein energy in formula 3 , and $65 \%$ in formula 4 . Formulas 2 and 5 were designed to provide higher energy intakes of $155 \mathrm{kcal} / \mathrm{kg}$ per day when fed at $180 \mathrm{~mL} / \mathrm{kg}$ per day, with nonprotein energy as $35 \%$ and $65 \%$ from $\mathrm{CHO}$, respectively (Table 1).

Experimental design. The infants were studied in the Infant Physiology Laboratory at Children's Hospital of New York. Six-hour daytime sleep studies were performed at 2-wk intervals, beginning when the infant reached full enteral intake of $180 \mathrm{~mL} / \mathrm{kg}$ per day and continuing until discharge. The mean postconceptional age at the time of first and second studies were $33.2 \pm 1.8$ and $35.0 \pm 1.5 \mathrm{wk}$, respectively. The postnatal ages were $21.7 \pm 11.5$ and $35.8 \pm 10.5 \mathrm{~d}$, respectively. Each study comprised two sequential 3 -h periods of observation interrupted by a feeding period. Infants were randomly assigned to the supine or prone position for the first 3-h epoch; the position was then reversed in the second 3-h epoch. They remained in their assigned positions throughout the interfeed period, and no further manipulations were performed.

Table 1. Characteristics and dietary intakes of the study population by groups*

\begin{tabular}{|c|c|c|c|c|c|}
\hline Characteristic & $\begin{array}{c}\text { Group } 1 \\
130 \mathrm{kcal} / \mathrm{kg} / \mathrm{d} \\
35 \% \mathrm{CHO} \\
(n=12)\end{array}$ & $\begin{array}{c}\text { Group } 2 \\
155 \mathrm{kcal} / \mathrm{kg} / \mathrm{d} \\
35 \% \mathrm{CHO} \\
(n=14)\end{array}$ & $\begin{array}{c}\text { Group } 3 \\
130 \mathrm{kcal} / \mathrm{kg} / \mathrm{d} \\
50 \% \mathrm{CHO} \\
(n=14)\end{array}$ & $\begin{array}{c}\text { Group } 4 \\
130 \mathrm{kcal} / \mathrm{kg} / \mathrm{d} \\
65 \% \mathrm{CHO} \\
(n=12)\end{array}$ & $\begin{array}{c}\text { Group } 5 \\
155 \mathrm{kcal} / \mathrm{kg} / \mathrm{d} \\
65 \% \mathrm{CHO} \\
(n=12)\end{array}$ \\
\hline Gestational age (wk) & $31.2 \pm 2.7$ & $30.4 \pm 2.6$ & $30.3 \pm 2.2$ & $29.4 \pm 3.1$ & $31.6 \pm 1.8$ \\
\hline Study weight $(\mathrm{g})$ & $1827 \pm 196$ & $1799 \pm 104$ & $1868 \pm 112$ & $1925 \pm 153$ & $1885 \pm 174$ \\
\hline Study age (PCA) (wk) & $34.8 \pm 1.4$ & $34.0 \pm 1.7$ & $34.2 \pm 1.5$ & $34.4 \pm 1.5$ & $34.9 \pm 1.1$ \\
\hline CHO intake $(\mathrm{g} / \mathrm{kg} / \mathrm{d})$ & $9.1 \pm 0.1$ & $11.2 \pm 0.3$ & $12.9 \pm 0.2$ & $16.8 \pm 0.1$ & $20.4 \pm 0.1$ \\
\hline Fat intake $(\mathrm{g} / \mathrm{kg} / \mathrm{d})$ & $7.8 \pm 0.19$ & $9.5 \pm 0.05$ & $6.1 \pm 0.27$ & $4.3 \pm 0.02$ & $5.4 \pm 0.03$ \\
\hline
\end{tabular}

* Results are mean \pm SD for $n=64$ infants.

Abbreviation used: PCA, postconceptional age. 
Experimental protocol. Infants were brought to the laboratory adjacent to the nursery at approximately 0730 , at which time electrodes for recording ECG, impedance respiration, EEG, and body temperature were attached and linked to an analog to digital converter. Continuous digital records were logged to a microcomputer. Infants were then placed in a radiantly warmed, clear plastic incubator in which ambient temperature was monitored, and were maintained under thermoneutral conditions. No physical constraints such as swaddling were used during the study period. Studies began after the 0800 feeding and continued until the 1400 feeding. The studies were interrupted for the 1100 feeding, after which sleeping position was changed. The volume and composition of the two feeds were identical. Sleep state coding began approximately $10 \mathrm{~min}$ after the 0800 feeding, continued until the 1100 feeding, resumed after the 1100 feeding, and terminated before the 1400 feeding. Behavior codes were assigned for approximately 6 consecutive $h$ by one of the three investigators, who coded behavioral state once each minute, using a scoring system developed and validated in our laboratory (25).

Coding of behavioral state. Briefly, AS was coded whenever at least one rapid eye movement was observed during the minute. In addition to small body movements typical of AS, movements of whole extremities and the torso were found in this state. Stretching, yawning, whimpering, sucking, and grimacing were also present occasionally. QS was designated when the infant was asleep without rapid eye movements. During QS the infant was relaxed and appeared "rag-doll" floppy; movements were limited to startles and nonnutritive sucking or jaw jerks. IND was coded when small body movements were observed, without rapid eye movements. Codes were also assigned for minutes in which infant appeared to be $\mathrm{AW}$, when they were crying or fussing (CRY), and for feeding periods.

Data analysis. A total of $300 \mathrm{~min}$ of data were analyzed for each study, i.e. from 10 to $160 \mathrm{~min}$ after completion of feeding in each sleeping position. The timing of the completion of the feeding was noted precisely. Minute-by-minute state codes for all individual studies were aligned to the time after feeding, and the percentage of the study population assigned to each state at each postprandial minute was computed for both prone and supine positions. Two studies from each patient, separated by $2 \mathrm{wk}$, were included in the calculation of these minute-byminute percentages, one beginning in the prone position and one in the supine, thus each infant contributed twice to each of these percentages. Mean state percentages in prone and supine position for the total study period were compared using paired $t$ test.
The effects of body position and time after feed on state distribution were evaluated by comparing the probability of being in a particular behavioral state during prone and supine positions for every postprandial minute, using $\chi^{2}$ analysis. Mean probabilities of being in a particular state for each diet group were calculated from the individual studies. The effects of diet on overall sleep distribution and the specific effect of body position, i.e. prone and supine, were compared at various $\mathrm{CHO}$ and fat intakes using ANOVA. With $\mathrm{CHO}$ and fat intakes as independent factors, a one-way ANOVA was conducted for each behavioral state. Similar analyses were performed for position-specific behavioral state with different dietary intakes. When ANOVA was significant $(p<0.05)$, post hoc paired $t$ tests were performed to elucidate the nature of these interactions.

Finally, to examine the influence of possible interactions between the quality of the diet and the sleeping position on the temporal organization of the sleep cycle, we focused on the immediate postfeeding interval, i.e. minutes 10 to 100 . On visual inspection of the ensemble plots of the groups' mean percentages of QS and AS versus time after feeding, the diet groups appeared to vary in both the overall distribution and the peak incidence of both QS and AS. Three-minute moving averages of the probabilities of being in AS and QS were computed for each diet group for each position. The peak incidence for each group, i.e. the maximum likelihood of being in a particular state during the postprandial period, and the average incidence during this postprandial period in prone and supine position were then related to mean group $\mathrm{CHO}$ intakes using simple linear regression.

\section{RESULTS}

Effects of posture on state distribution. The overall percent distribution of sleep-wake states for both sleeping positions was that expected for a population of LBW infants $(17,20)$. The vast majority of minutes were coded as AS (71.6\%), followed by QS (14.9\%), AW (5.7\%), IND (4.4\%), and CRY (3.4\%). With respect to sleeping position three significant differences in state distribution were observed, as shown in Table 2. The probabilities of being in states AW and CRY were both significantly increased $(p<0.0001)$ when infants were placed in supine position. In contrast, the probability of QS almost doubled in the prone position $(p<0.0001)$. The probabilities of being in IND and AS were not significantly different between the two positions.

Effects of posture and time after feed on state distribution. The probabilities of being in QS and AS during the postpran-

Table 2. State distribution in prone and supine sleeping positions*

\begin{tabular}{lrrrr}
\hline \multicolumn{1}{c}{ State } & \multicolumn{1}{c}{ Prone } & Supine & $t$ statistic & $p$ value \\
\hline Quiet sleep (\%) & $18.7 \pm 0.7$ & $11.1 \pm 0.6$ & 10.2 & 1.7 \\
Indeterminate sleep (\%) & $4.8 \pm 0.3$ & $4.5 \pm 0.3$ & 1.0 & NS \\
Active sleep (\%) & $72.1 \pm 0.8$ & $70.9 \pm 1.5$ & -7.8 & NS \\
Awake (\%) & $2.9 \pm 0.4$ & $8.4 \pm 0.7$ & -5.3 & $<0.0001$ \\
Cry (\%) & $1.4 \pm 0.3$ & $5.3 \pm 0.7$ & $<0.0001$ \\
\hline
\end{tabular}

$*$ Results are mean \pm SEM. 
dial period are summarized in the plots in Figure 1. Bolus feeding appeared to entrain the cyclic changes in sleep states. The peak incidence in QS occurred roughly $45 \mathrm{~min}$ after the feeding, and this postprandial entrainment appeared to be more prominent when the infant was placed in the prone position. These position-related differences in QS were significant during two periods in the prandial cycle, i.e. between postprandial minutes 30 and 59 ( $\chi^{2}$ range, 5.5-23.5; all $\left.p<0.01\right)$ and minutes 125 and 153 ( $\chi^{2}$ range, 5.1-20.4; all $\left.p<0.02\right)$. AS was significantly decreased in the prone position during minutes 33 and $47\left(\chi^{2}\right.$ range, 4.7-15.7; all $\left.p<0.02\right)$ and minutes 129 and 135 ( $\chi^{2}$ range, 5.6-9.7; all $\left.p<0.01\right)$. In contrast, the decreased probability of occurrence of nonsleep states (AW and $\mathrm{CRY}$ ) during prone positioning was distributed throughout the postprandial period and did not show any such temporal pattern.

Effects of quality of diet and posture on state distribution. As summarized in Table 3, the probability of being in QS increased significantly as $\mathrm{CHO}$ intake increased $(F=5.3 ; p<$ 0.02), whereas the AS and nonsleep states, i.e. AW and CRY, showed no trends. Post hoc tests demonstrated that this QS distribution interaction was attributed to $\mathrm{CHO}$ intakes of 9.1 $\mathrm{g} / \mathrm{kg}$ per day and $20.4 \mathrm{~g} / \mathrm{kg}$ per day. Also, as CHO intake increased, mean time spent in QS during supine position increased (from $8.6 \%$ to $12.5 \% ; F=13.3 ; p<0.02$ ), and a strong trend in the same direction was noted for the prone position $(F=8.7 ; p=0.06)$ (Table 4$)$. No significant interaction of this QS-enhancing effect of CHO intake was observed in different sleeping positions $(F=1.6)$. No significant differences in sleep state distribution were observed at different fat intakes.

Effects of diet, posture, and time after feeding on state distribution. As shown in Figure 2, during the postfeeding period (minutes 10-100), in the prone position, the maximum likelihood of being in QS, i.e. peak QS during the postprandial
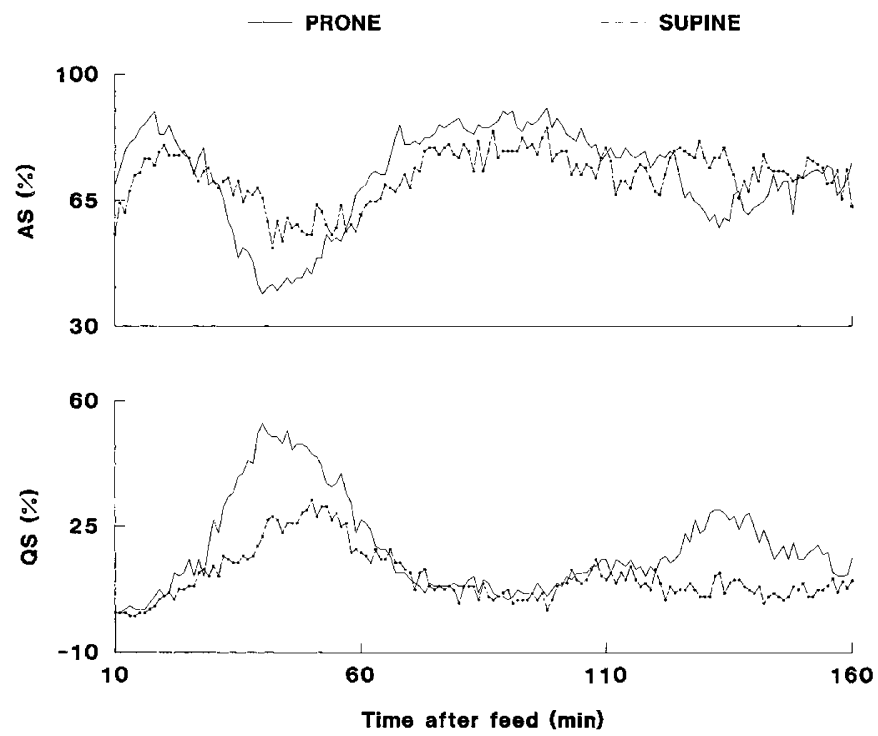

Figure 1. Probability of being in QS and AS during the postprandial period (10-160 min). Solid lines are results when the infants were sleeping in the prone position, and interrupted lines are data obtained when infants were in the supine position. period, correlated significantly with $\mathrm{CHO}$ intake (Peak QS = $1.8 \times \mathrm{CHO}$ intake $\left.+36.5 ; p<0.005 ; r^{2}=0.95\right)$. Similarly, in the prone position, during the postfeeding period (minutes 10-100), the average incidence of QS also correlated significantly with $\mathrm{CHO}$ intake (Mean QS $=0.44 \times \mathrm{CHO}$ intake + 18.4; $p<0.02 ; r^{2}=0.80$; Fig. 3). This relationship was not distinguishable in the supine position. Similar analyses for other behavioral states showed no such interactions with quality of diet and posture during the postprandial period.

\section{DISCUSSION}

The results of this study are consistent with earlier observations from several laboratories, including our own, that sleep architecture and state organization are altered by body position and time after feeding (17-24). The data from these studies indicate that another experimental covariate, the absolute amount of nonprotein energy, also influences the effects of the prandial cycle on sleep organization. Increasing absolute $\mathrm{CHO}$ intakes, at constant protein intakes, is associated with increased amounts of QS during the interfeed interval. In addition, in the prone position, $\mathrm{CHO}$ intake correlates positively with the peak and the average incidence of QS during the postprandial period. Interestingly, the likelihood of QS occurring in the absorptive period is increased with increased CHO intake, and this trend is found during both time periods when QS is most likely to occur. The effect of $\mathrm{CHO}$ could be characterized as an amplification of underlying postprandial cyclicity of QS and AS.

The effects of diet on overall sleep distribution reinforce results reported for LBW infants $(17,18)$ and healthy newborns (19-21). It remains unclear why body position leads to differences in sleep architecture. It has been proposed that in the prone position there is an increase in arousal threshold to both internal (e.g. gastroesophageal reflux) and external (e.g. sound) stimuli $(19,22,26)$. Some have noted no change in arousal related to body position (27). The relationships among arousal threshold (awakening), time spent awake, and body position are unclear, and likely complex and interactive. It may be that in the prone position the sleep is "deeper" and the arousal threshold to move from sleep to a state of wakefulness is increased. Conversely, the increased time spent in QS in the prone position may decrease awakening through its suppression of AS, which is the state from which most arousals occur during the first 6 mo (28). On the other hand, because awakenings are more likely to be followed by AS than QS $(23,28)$, increases in awakenings in the supine position may indirectly lead to decreases in the amount of QS. We did not characterize the effects of diet or position on arousal threshold (awakening), although time spent $\mathrm{AW}$ in supine position was greater than in the prone position.

The effects of quality of nonprotein energy on QS were found most clearly in the absorptive period, i.e. during the beginning of the interfeed interval. Also, there was no significant change in the amount of AS in relation to body position. These observations suggest that the decreases in QS in supine position may not solely be related to more frequent arousals; other factors such as feeding and quality of diet may play a 
Table 3. Effects of CHO intake on distribution of behavioral activity states*

\begin{tabular}{lccccc}
\hline \multicolumn{1}{c}{ State/ CHO intake } & Group 1 $(9.1 \mathrm{~g} / \mathrm{kg} / \mathrm{d})$ & Group 2 $(11.2 \mathrm{~g} / \mathrm{kg} / \mathrm{d})$ & Group 3 $(12.9 \mathrm{~g} / \mathrm{kg} / \mathrm{d})$ & Group $4(16.8 \mathrm{~g} / \mathrm{kg} / \mathrm{d})$ & $\mathrm{Group} 5(20.4 \mathrm{~g} / \mathrm{kg} / \mathrm{d})$ \\
\hline Quiet sleep (\%) & $12.6 \pm 1.1$ & $15.2 \pm 1.0$ & $16.1 \pm 1.2$ & $14.4 \pm 1.2$ & $17.9 \pm 1.1 \dagger$ \\
Indeterminate sleep (\%) & $3.7 \pm 0.5$ & $4.9 \pm 0.6$ & $4.2 \pm 0.4$ & $5.4 \pm 0.8$ & $4.4 \pm 0.5$ \\
Active sleep (\%) & $71.6 \pm 2.1$ & $71.3 \pm 1.7$ & $72.0 \pm 1.6$ & $73.9 \pm 2.0$ & $68.3 \pm 1.3$ \\
Awake (\%) & $8.2 \pm 1.5$ & $4.9 \pm 0.9$ & $5.4 \pm 0.8$ & $4.1 \pm 0.7$ & $5.9 \pm 0.9$ \\
Cry (\%) & $3.9 \pm 1.1$ & $3.8 \pm 1.0$ & $2.3 \pm 0.4$ & $2.2 \pm 0.9$ & $4.0 \pm 0.2$ \\
\hline
\end{tabular}

* Results are mean \pm SEM.

$\dagger$ Group 1 vs Group 5; $p<0.02$.

Table 4. Effects of CHO intake on distribution of QS in supine and prone position*

\begin{tabular}{lccccc}
\hline QS-position/CHO intake & Group 1 $(9.1 \mathrm{~g} / \mathrm{kg} / \mathrm{d})$ & Group 2 $(11.2 \mathrm{~g} / \mathrm{kg} / \mathrm{d})$ & Group 3 $(12.9 \mathrm{~g} / \mathrm{kg} / \mathrm{d})$ & Group $4(16.8 \mathrm{~g} / \mathrm{kg} / \mathrm{d})$ & $\mathrm{Group} 5(20.4 \mathrm{~g} / \mathrm{kg} / \mathrm{d})$ \\
\hline Quiet sleep-supine (\%) & $8.6 \pm 0.7$ & $9.7 \pm 0.5$ & $10.5 \pm 0.6$ & $10.1 \pm 0.6$ & $12.5 \pm 0.7 \dagger$ \\
Quiet sleep-prone (\%) & $15.0 \pm 1.1$ & $18.4 \pm 1.1$ & $19.8 \pm 1.2$ & $18.7 \pm 1.5$ & $22.1 \pm 1.4+$ \\
\hline
\end{tabular}

* Results are mean \pm SEM.

$\dagger$ Group $1 v s$ group 5, $p<0.02$

$\$$ Group 1 vs group 5; $p=0.06$.

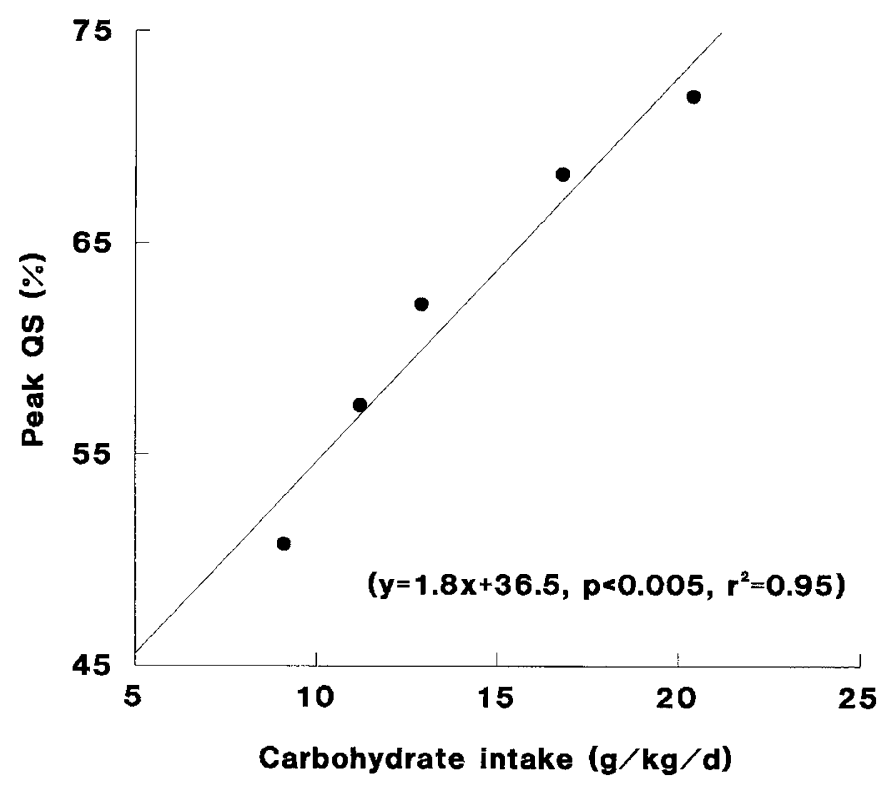

Figure 2. Relationship between the maximum likelihood of being in QS (peak QS) in the prone sleeping position and $\mathrm{CHO}$ intake during postprandial minutes $10-100$.

role. Feeding can serve as entraining stimulus for sleep cycles in infants. As shown by others (23), our data indicate that the peak probability of QS is at approximately $45 \mathrm{~min}$ after feeding, with the second peak approximately $1 \mathrm{~h}$ later. These results suggest two peaks in the incidence of QS during the interfeed interval, one within the second half-hour after feeding and the second near the end of the interfeed interval. This pattern is most distinct when infants are in the prone position. Thus, body position seems to modulate the effects of feeding on activity.

The traditional assumption that healthy infants at rest are in a relatively steady-state with respect to physiology and behavior is an oversimplification $(29,30)$. At any point in time after feeding, depending on body position and the amount and quality of the feed, many physiologic measurements will differ. During the absorptive period, as nutrients are transported, absorbed, metabolized, or stored, the infant (particularly the growing infant) expends more energy. This increment in en-

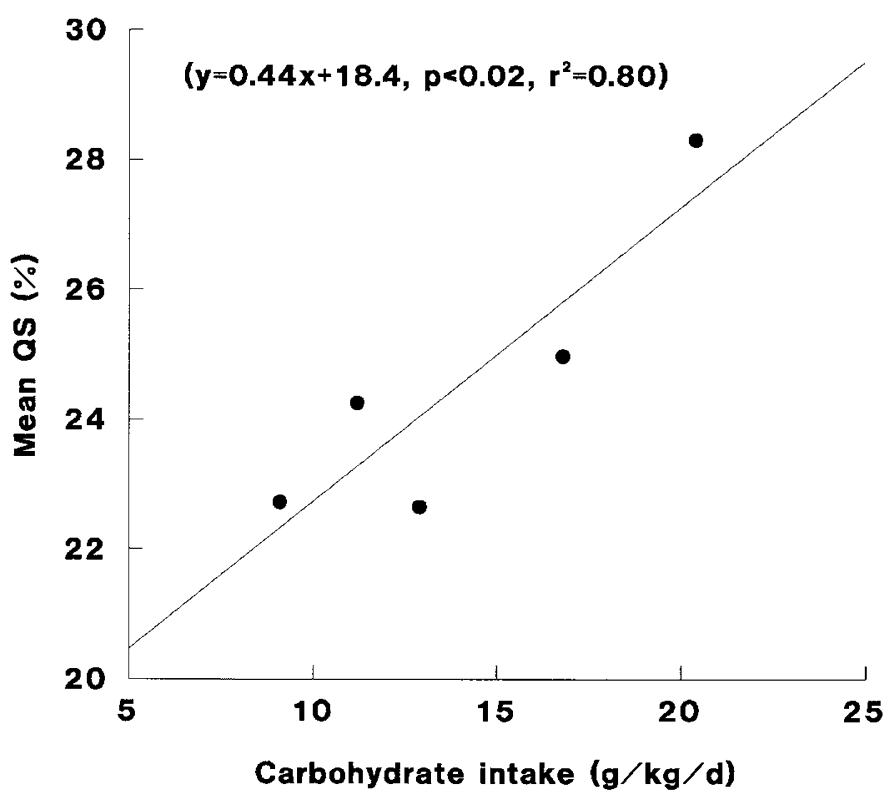

Figure 3. Relationship between the average incidence of QS (mean QS) in the prone sleeping position and $\mathrm{CHO}$ intake during postprandial minutes $10-100$.

ergy expenditure, known as diet-induced thermogenesis, and the thermic effect of feeding or specific dynamic action varies with macronutrient intake. Parallel changes in heart rate, respiratory rate, temperature, and RQ (29) are noted during this period.

Less well-defined are the temporal profiles of the accompanying biochemical effects of bolus feedings, i.e. the phasic increases in circulating levels of glucose, amino acids, lipids, and their metabolites, humoral mediators of anabolic activity, changes in acid base status, etc. It is reasonable to hypothesize that variations in the biochemical and physiologic interactions in response to feeding might influence sleep architecture in newborn infants. Brain serotonin content has been related to the flux of tryptophan across the blood-brain barrier, which in turn is related to the plasma concentration of tryptophan relative to the other large neutral amino acids. Because insulin promotes the utilization of all large neutral amino acids except tryptophan, the relative concentration of tryptophan increases 
during the postprandial surge of insulin $(31,32)$. Through this mechanism, increased $\mathrm{CHO}$ intake would be expected to lead to increased brain serotonin, and, in turn, to increased QS (33). The enhanced QS found during the postfeeding period in these LBW infants may be related to central serotonergic activity. Further support to this concept is provided by the observation that infants fall asleep sooner after a tryptophan and high $\mathrm{CHO}$ $(10 \%$ glucose $)$ feed, than after a valine and $5 \%$ glucose feed or when receiving a balanced formula (Similac 20; Ross Laboratories, Columbus, OH, U.S.A.) $(34,35)$.

In our study, the overall positive correlation between $\mathrm{CHO}$ intake and QS distribution was found in both supine and prone positions, but during the first postprandial entrainment period, the likelihood of being in QS at peak entrainment and the average incidence of QS were greater at higher $\mathrm{CHO}$ intakes in the prone position only. This relationship was not distinguishable in the supine position. These position-specific outcomes may be related to position-dependent differences in thermal profile or circulatory patterns. How these interactions influence vulnerability to SIDS remains speculative. To improve our understanding of the influence of the interactions among diet, body position, time after feeding and state organization on the underlying mechanisms that predispose to SIDS, further studies in LBW infants and term infants at 2 to 4 mo corrected age, when diurnal rhythms are more fully developed and the risk for SIDS is greater, are needed.

\section{REFERENCES}

1. Guyer B, Freedman MA, Strobino DM, Sondik EJ 2000 Annual summary of vital statistics-trends in the health of Americans during the 20th century. Pediatrics 106:1307-1317

2. Malloy MH, Hoffman HJ 1995 Prematurity sudden death syndrome, and age of death. Pediatrics 96:464-471

3. Hoffman HJ, Damus K, Hillman L, Kongrad E 1988 Risk factors for SIDS: results of the National Institute of Child Health and Human Development SIDS Cooperative Epidemiological Study. Ann N Y Acad Sci 533:13-30

4. Lipsky CL, Gibson E, Cullen JA, Rankin K, Spitzer AR 1995 The timing of SIDS deaths in premature infants in urban population. Clin Pediatr 34:410-414

5. Bayes BJ 1974 Prone infants and SIDS. N Engl J Med 290:693-694

6. [No authors listed] 1991 A scientific review of the association between prone sleeping position and sudden infant syndrome. J Paediatr Child Health 27:323-324

7. Dwyer T, Posonby AL, Gibbons LE, Newman NM 1991 Prone sleeping position and SIDS: evidence from recent case-control and cohort studies in Tasmania. J Paediatr Child Health 27:340-343

8. Dwyer T, Posonby AL, Newman NM, Gibbons LE 1991 Prospective cohort study of prone position and sudden infant syndrome. Lancet 337:1244-1247

9. Mitchell EA, Scragg R, Stewart AW, Becroft DM, Taylor BJ, Ford RP, Hasall IB, Barry DM, Allen EM, Roberts AP 1991 Results from the first year of the New Zealand cot death study. N Z Med J 104:71-76
10. [No authors listed] 1992 American Academy of Pediatric Task Force on Infant Positioning and SIDS: positioning and SIDS. Pediatrics 89:1120-1126

11. Willinger M, Hoffman HJ, Wu KT, Hou JR, Kessler RC, Ward SL, Keens TG, Corwin MJ 1998 Factors associated with the transition to non prone sleep position of infants in the United States: the National Infant Sleep Position Study. JAMA 280:329-335

12. Hutchison AA, Ross KR, Russell G 1979 The effect of posture on ventilation and lung mechanics in preterm and light-for-date infants. Pediatrics 64:429-432

13. Martin RJ, Herrell N, Rubin D, Fanaroff A 1979 Effect of supine and prone positions on arterial oxygen tension in the preterm infant. Pediatrics 63:528-531

14. Wagaman MJ, Shutack JG, Moomjian AS, Schwartz JG, Shaffer TH, Fox WW 1979 Improved oxygenation and lung compliance with prone positioning of neonates. J Pediatr 94:787-791

15. Kurlak LO, Ruggins NR, Stephenson TJ 1994 Effect of nursing position on incidence, type, and duration of clinically significant apnea in preterm infants. Arch Dis Child Fetal Neonatal Ed 71:F16-F19

16. Martin RJ, DiFiore JM, Korenke CB, Randal H, Miller MJ, Brooks LJ 1995 Vulnerability of respiratory control in healthy preterm infants placed supine. J Pediatr 127:609-614

17. Masterson J, Zucker C, Schulze K 1987 Prone supine positioning effects on energy expenditure and behavior of low birth weight infants. Pediatrics 80:689-692

18. Myers MM, Fifer WP, Schaeffer L, Sahni R, Ohira-Kist K, Stark RI, Schulze KF 1998 Effects of sleeping position and time after feeding on the organization of sleep/wake states in prematurely born infants. Sleep 21:343-349

19. Brackbill Y, Douthitt TC, West H 1973 Psychophysiologic effects in the neonate of prone versus supine placement. J Pediatr 82:82-84

20. Hashimoto T, Hiura K, Endo S, Fukuda K, Mori A, Tayama M, Miyao M 1983 Postural effects on behavioral states of newborn infants: a sleep polygraphic study. Brain Dev 15:286-291

21. Amemiya F, Vos JE, Prechtl HF 1991 Effects of prone and supine position on heart rate, respiratory rate and motor activity in full term infants. Brain Dev 3:148-154

22. Kahn A, Rebuffat E, Sottiaux M, Dufour D, Cadranel S, Reiter F 1991 Arousal induced by proximal esophageal reflux in infants. Sleep 14:39-42

23. Harper RM, Hoppenbrouwers T, Bannett D, Hodgeman J, Sterman MBX, McGinty DJ 1977 Effects of feeding on state and cardiac regulation in the infant. Dev Psychobiol 10:507-517

24. Schulze KF, Kashyap S, Sahni R, Myers M, Fifer W 1996 Diet, sleep and the developing autonomic nervous system. In: Johnson P (ed) Proceedings of the 3rd Congress of the European Society for Study of Infant Death. Holywell Press, Oxford, UK, pp 36-42

25. Stefanski M, Schulze KF, Bateman D, Kairam R, Pedley T, Masterson J, James LS 1984 A scoring system for states of sleep and wakefulness in term and preterm infants. Pediatr Res 18:58-63

26. Newman NM, Trinder JA, Phillips KA, Jordan K, Cruickshank J 1989 Arousal deficit: mechanism of the sudden death syndrome? Aust Paediatr J 25:196-201

27. Jeffery HE, Megevand A, Page H 1999 Why the prone position is a risk factor for sudden infant death syndrome. Pediatrics 104:263-269

28. Ficca G, Fagioli I, Giganti F, Salzarulo P 1999 Spontaneous awakenings from sleep in the first year of life. Early Hum Dev 55:219-228

29. Schulze K, Stefanski M, Masterson J, Spinnazola R, Ramakrishan R, Dell RB, Heird WC 1987 Energy expenditure, energy balance, and composition of weight gain in low birth weight fed diets of different protein and energy content. J Pediatr 110:753-759

30. Schulze K, Stefanski M, Masterson J, Kashyap S, Sanocka U, Forsyth M, Ramakrishnan R, Dell R 1986 An analysis of the variability in estimates of bioenergetic variables in preterm infants. Pediatr Res 20:422-427

31. Fernstrom JD, Wurtman RJ 1971 Brain serotonin content: increase following ingestion of carbohydrate diet. Science 174:1023-1025

32. Fernstrom JD, Faller DV 1978 Neutral amino acids in the brain: changes in response to food ingestion. J Neurochem 30:1531-1538

33. Wauquier A, Dugovic C 1990 Serotonin and sleep-wakefulness. Ann NY Acad Sci 600:447-458

34. Yogman MW, Zeisel SH, Roberts C 1982-83 Assessing effects of serotonin precursors on newborn behavior. J Psychiatr Res 17:123-133

35. Yogman MW, Zeisel SH 1983 Diet and sleep patterns in newborn infants. N Engl J Med 309:1147-1149 